\title{
Alternative theoretical models for ESOs valuation: Further evidence
}

\author{
Marco Pagani, and Themis D. Pantos* \\ *Accounting and Finance Department, College of Business, San Jose State University, One \\ Washington Square, San Jose CA, 95192-0066, USA. \\ Tel: (408) 924-3472, Fax: (408) 924-3463 \\ Received (in revised form): 7th February, 2008
}

\begin{abstract}
Dr Marco Pagani is an assistant professor of finance in the Department of Accounting and Finance at San Jose State University, San Jose, USA. Professor Pagani received his PhD in Finance from Georgia State University, Atlanta, USA; his MSc in Finance from HEC, University of Montreal, Montreal, Canada; and his BBA from the University Lyon II, Lyon, France. Dr Pagani's research and teaching interests are in the areas of Investments, Capital Markets and Institutions, and Derivative Securities.
\end{abstract}

Dr Themis D. Pantos is an associate professor of finance in the Department of Accounting and Finance, College of Business, at the San Jose State University, California, USA. He has published numerous articles in various peer-reviewed finance, taxation and economics journals. Dr Pantos' research and teaching interests are in the areas of Capital Markets and Institutions, International Finance and Derivative Securities.

\section{Practical applications}

This article enhances our understanding of the proper valuation of Employee Stock Options (ESOs) because it yields robust estimates in the presence of forfeiture, marketability, transferability and turnover rates. The study would be of value to academics, Certified Public Accountants (CPAs), Chartered Financial Analysts (CFAs), Internal Revenue Service (IRS) specialists, tax practitioners and regulators.

\begin{abstract}
Pantos et al. (2003) argue that there exists an alternative class of theoretical models that yield better results, in relation to employee stock options (hereafter, ESOs) valuation, than those obtained by the Black and Scholes and the Binomial model. In this paper, the option valuation estimates yielded by the three models are contrasted and compared for efficiency, reliability and robustness. The results indicate that the Black and Scholes and the Binomial Model overestimate the ESOs valuation. Furthermore, the results stipulate that when the concepts of forfeiture, marketability, transferability and turnover rate are
\end{abstract}

taken into consideration at the grant date, the estimates yielded by the theoretical model developed by Pantos (2005) are superior to the estimates obtained by the employment of the aforementioned models. Journal of Derivatives \& Hedge Funds (2008) 14, 150-155. doi:10.1057/jdhf.2008.12

Keywords: employee stock options; forfeiture; marketability; transferability and turnover rate

\section{INTRODUCTION}

Perhaps no other area of modern finance theory has recently commanded so much attention as
Journal of Derivatives \& Hedge Funds, Vol. 14 No. 2, 2008 , pp. 150-155 (C) 2008 Palgrave Macmillan Ltd 1753-9641 
the valuation of the employee stock options (hereafter, ESOs) problem. Simply put, the main focus of this academic research is how to value the options on the date they are granted and what theoretical model should be employed in order to derive robust, efficient and reliable option price estimates.

A variety of theoretical models appeared in the modern financial economics literature in the last two decades that aimed to solve this particular and controversial valuation problem. Among the many theoretical models, two have commanded most of the attention of the accounting academic researchers, certified public accountants, chartered financial analysts, Tax practitioners and internal revenue service specialists: (1) The Black and Scholes ${ }^{1}$ model derived in a continuous time-framework and (2) The Binomial model derived in a discrete time framework in the academic writings of Cox, Ross and Rubinstein ${ }^{2}$ and Rendleman and Bartter, ${ }^{3}$ respectively.

Pantos et al., ${ }^{4}$ and Pantos, ${ }^{5}$ and several other authors ${ }^{6}$ indicate in their academic studies that the underlying assumptions of the Black and Scholes and the Binomial model are either unrealistic or inappropriate to be used in the ESOs valuation or even in the restricted ESOs context. For instance, in their study Pantos et al. (2003) maintain (in the fourth paragraph, p. 533) that:

'... The Black and Scholes model was not designed for measuring public companies' restricted ESOs, never mind privately held stock options. The Black and Scholes model was designed to deal with European-style traded options, in which the exercise date is designated as only one date (maturity).

Underpinning the Black and Scholes model are the assumptions that the options are fully marketable and transferable, there are no forfeitures of the options, and have relatively short terms (90 days to six months). Almost none of these conditions are true for a restricted ESO. Therefore, it is ludicrous to apply a model that works for one type of asset to a totally different animal. It would be like applying a concept that worked under water (eg, Charles's Law or Boyle's Law) where pressure increases one atmosphere every 32 feet, to an outer space experiment where gravity is constant at virtually zero atmospheres of pressure'.

Pantos et al. (2003) proceed with the analysis and further state (in the sixth paragraph, p. 533) that:

'...What it doesn't reflect is employee turnover rate and how long after the grant date the optionee must wait before exercising. It also ignores the fact that these options are neither marketable nor transferable. Also, restricted ESOs may be subject to SEC rules that even when they become marketable, may significantly limit their liquidity. These last three factors have led to, at least in the tax arena, 25 per cent to 40 per cent valuation discounts, yet they are not yet applied or acceptable for financial statements in determining value of a restricted ESO'.

The purpose of this paper is to show that ESOs can actually be valued correctly if a theoretical model incorporates, parameterises and quantifies restrictions that reflect important issues such as employee turnover rate, forfeiture, transferability and marketability. The paper proceeds as follows. The next section briefly 
introduces the Black and Scholes, the Binomial and the Pantos ${ }^{7}$ theoretical models. The penultimate section contrasts the ESOs results obtained by the employment of the three valuation models. The final section concludes the paper and offers direction for further research on ESOs valuation.

\section{MODEL INTRODUCTION}

The Black and Scholes model that revolutionised the field of modern finance relies on a set of unrealistic assumptions, such as: (i) the financial markets are frictionless (eg, no transaction costs exist in the marketplace), (ii) the borrowing rate $r_{b}$ is equal to the lending rate $r_{l}$ and both are equal to the risk free rate $r_{f}$ and (iii) the net profits $\pi$ (eg, the amount of profits exceeds the amount of losses) of all individual, institutional and corporate agents are subjected to the same tax rate, $\tau$.

Pantos et al. (2003), Pantos (2005), Hull and White (2004), Cox Ross and Rubinstein (1979) and Rendleman and Bartter (1979) stipulate in their studies that the Black and Scholes model was developed under the assumption of risk neutrality and was derived in a continuous time-framework. The model provides values for the two rooted components of the traded call and put options: (i) the intrinsic value and (ii) the time value component. The time value component is what commonly refers to the financial economics literature as the speculative premium component. The intrinsic value component ${ }^{8}$ is denoted by the difference between the underlying terminal stock price $S_{T}$ and the exercise price embedded in the option $\mathrm{X}$, respectively.

The time value component on the other hand incorporates a set of important economic variables namely: the current stock price $\left(S_{0}\right)$, the strike or exercise price $(X)$, the volatility of the stock price $(\sigma)$, the time to expiration $(T)$ and finally the current risk-free interest rate $\left(r_{f}\right)$ for the expected life of the option. The time value component can be valued by employing several numerical procedures. ${ }^{9}$

The Binomial model is employed in the financial economics literature to value American-style Options on stocks and is also based on the so-called risk-neutral valuation assumption. It is a numerical model that shows how the price of a hypothetical stock will evolve over a certain amount of time. The behaviour of the underlying stock price is depicted on a tree diagram. The stock price at any time can take only two possible values dictated by the upward multiplicative factor $\mu$ and the downward multiplicative factor $\chi$, respectively. The stock price is assumed to go 'up' or 'down' at the end of any time period. Only two outcomes are possible and the multiplication factor upwards should all the time exceed the multiplicative factor downwards. The price path of the underlying stock over the time period depends on the multiplicative factors upward and downward $\mu$ and $\chi$ respectively, the risk-neutral probability in every step of the Binomial Lattice $p$, the risk free rate $r_{f}$, with awarded values for $\mu=1 / \chi, p=q-\chi / \mu-\chi$ and $\mu>\chi .{ }^{10}$

The model introduced in Pantos (2005) is a modified version of the Jennergren and Naslund ${ }^{11}$ model. It incorporates a random variable $\theta$, which is quantifiable and denotes the employee 'turnover rate' or the 'exit-rate', respectively. This random variable can be statistically estimated by obtaining historical data from any division of a high-technology firm, or any industry sector that follows the standardised industry classification system and has granted 
ESOs to its executives or any other kind of employees.

An elegant scheme of Pantos' (2005) model is that it utilises the Jennergren and Naslund model in combination with a Forward Start Option Factor, (hereafter, FSOF) given the certain grant ESO date. This FSOF factor $\phi$ is proportional to the ratio of the terminal stock price to the exercise price $\phi=S_{r} / X$ and is similar to the factor used by Rubinstein. ${ }^{12}$ The FSOF factor $\phi$ reveals the time lag before an employee is allowed to exercise or vest in the options. Both the 'exit-rate' or 'turnover rate' random variable $\theta$ and the FSOF $\phi$ factor are adjusted by a discount factor 25 per cent $<\gamma<40$ per cent for the ESOs' lack of marketability/transferability and potential SEC limitations. ${ }^{13}$

\section{MODEL CALIBRATION AND PARAMETER ESTIMATION}

In order to contrast the ESOs results obtained by the use of the three theoretical valuation models we have chosen a hypothetical corporation by the name 'OMEGA Limited'. The corporation is a publicly traded high-technology firm that has recently granted to 'Dr Apollonius', a potential executive VP of the Finance Division, 100,000 ESOs at a strike price of $\$ 50$ per share when the grant date value is also $\$ 50$ per share. The company is facing 40 per cent stock price volatility, the risk free rate is 5 per cent that is equal to the cost to carry and the annual employee 'turnover rate' or exit rate is 15 per cent. In addition to this, the underlying stock pays no dividend and the options are vested 25,000 per year spanning a four-year time horizon. ${ }^{14}$

Reflecting all the aforementioned factors, the Black and Scholes model estimates the values of an ESO at the grant date as $\$ 9.11$ for the options vesting in one year, $\$ 13.14$ for options vesting in year 2, \$16.36 for options vesting in year 3 and $\$ 19.08$ for options vesting in year 4 . The Binomial model estimates the values of an ESO at the grant date as $\$ 8.69$ for the options vesting in one year, $\$ 12.92$ for options vesting in year 2 , $\$ 16.19$ for options vesting in year 3 and $\$ 18.93$ for options vesting in year 4 .

The Pantos (2005) theoretical model estimates the values of an ESO at the grant date as $\$ 5.81$ for the options vesting in one year, $\$ 7.30$ for options vesting in year $2, \$ 7.76$ for options vesting in year 3 and $\$ 7.85$ for options vested in year 4. On 100,000 options the value differential between the Black and Scholes or the Binomial and the Pantos model is roughly $\$ 724,250$

(Table 1).

The results obtained from the employment of the three models clearly indicate that the Black and Scholes model and the Binomial model overestimate the values of the ESOs and do not yield either reliable or robust and accurate ESOs estimates. In addition, the results have clearly shown the advantage of the Pantos' (2005) model that reflects in its structure important variables such as the employee turnover rate, forfeiture, marketability and transferability.

In addition to this, one can safely conclude that the high-technology firms, especially in Silicon Valley, have consistently paid larger amounts of money in order to cover the gap between the proper theoretical ESOs values and the overestimated values obtained by the Black and Scholes model and the Binomial model, over the vested life of the options. ${ }^{15}$ Therefore, neither the FASB nor the IASB should employ these models anymore, since they yield invalid and unreliable ESOs estimates. 
Table 1: Estimated ESOs values ${ }^{16}$

\begin{tabular}{|c|c|c|c|}
\hline $\begin{array}{l}\text { Option vested time } \\
\text { horizon }\end{array}$ & $\begin{array}{l}\text { The Black and } \\
\text { Scholes model }\end{array}$ & $\begin{array}{l}\text { The binomial } \\
\text { model }\end{array}$ & $\begin{array}{l}\text { The Pantos (2005) } \\
\text { model }\end{array}$ \\
\hline Year 1 & $\$ 9.11$ & $\$ 8.69$ & $\$ 5.81$ \\
\hline Year 2 & $\$ 13.14$ & $\$ 12.92$ & $\$ 7.30$ \\
\hline Year 3 & $\$ 16.36$ & $\$ 16.19$ & $\$ 7.76$ \\
\hline Year 4 & $\$ 19.08$ & $\$ 18.93$ & $\$ 7.85$ \\
\hline Parameter values & Notation & & \\
\hline$S_{T}=\$ 50$ & The current stock price & & \\
\hline$X=\$ 50$ & $\begin{array}{l}\text { The strike or exercise } \\
\text { price }\end{array}$ & & \\
\hline$T=4$ & The time to expiration & $\begin{array}{l}24 \text { Steps (six per } \\
\text { year } \times 4)\end{array}$ & \\
\hline$\sigma=40$ per cent & $\begin{array}{l}\text { The volatility of the } \\
\text { stock price }\end{array}$ & & $\begin{array}{l}\phi=S_{T} / X=50 / 50=1 \\
\text { FSOF factor }\end{array}$ \\
\hline \multirow[t]{2}{*}{$r_{f}=5$ per cent } & $\begin{array}{l}\text { The current risk-free } \\
\text { interest rate }\end{array}$ & & $\theta=15 \%$ The employee turnover rate \\
\hline & & & $\begin{array}{l}\gamma=25 \% \\
\text { The discount factor for marketability and } \\
\text { transferability }\end{array}$ \\
\hline
\end{tabular}

\section{CONCLUSION AND SUGGESTIONS FOR FURTHER RESEARCH}

We have compared and contrasted three alternative mathematical valuation models. The results indicate that the Black and Scholes model and the Binomial model overestimate the ESOs valuation. Furthermore, the results stipulate that when the concepts of forfeiture, marketability, transferability and turnover rate are taken into consideration at the grant date the estimates yielded by the Pantos (2005) theoretical model are much lower than the estimates of the aforementioned models.

Incrementally, the results suggest that hightechnology Silicon Valley firms have consistently paid larger amounts of money in order to cover the gap between the proper theoretical ESOs values and the overestimated values obtained by the Black and Scholes and the Binomial model respectively, over the vested life of the options.

An interesting research question will be of course the estimation (eg, historical or implied) of the turnover rate that reflects employee's behaviour at the high-technology firms that have granted ESOs to their employees. It also would be very interesting to observe and eventually analyse the compensation schemes associated with the high-technology firms in the near future. For instance, how many high-technology firms will abandon restricted stock options and switch to restricted stock grants, which are 
treated differently under the existing accounting rules? Another important research question to investigate is whether to monitor the behaviour of the high-technology firms and examine if they will award ESOs solely to upper management or will include the lesser rank employees in the near future.

\section{References and Notes}

1 Black, F. and Scholes, M. (1973) 'The Pricing of Options and Corporate Liabilities', Journal of Political Economy, Vol. 81, pp. 637-659.

2 Cox, J.C., Ross, S.A. and Rubinstein, M. (1979) 'Option Pricing: A Simplified Approach', Journal of Financial Economics, Vol. 7, pp. 229-264.

3 Rendleman, R. and Bartter, B. (1979) 'Two State Option Pricing', Journal of Finance, Vol. 34, pp. 10921110.

4 For more on this issue, see for instance Pantos, T.D., Stewart, K. and Mori, J. (2003) 'Alternative to BlackScholes for Valuing ESOs', Tax Notes 28th April, 2003 pp. 533-535.

5 Pantos (2005) 'ESO Valuation: The New Kid on The Block', Tax Notes 17th October, 2005, pp. 333-334.

6 See for instance, Hull, J.C. and White, A. (2004) 'How to Value Employee Stock Options', Financial Analysts Journal, Vol. 60, No. 1, pp. 8-24.

7 For more on this issue, see the study performed by Pantos ${ }^{5}$.

8 The payoff associated with this component is denoted by the $\max \left[S_{T}-X ; 0\right]$. If the underlying stock price exceeds the striking price, $S_{T}>X$ a call option is in the money and commands a positive value. If $S_{T}=X$ the option is at the money, and if $S_{T}<X$ the option is out of the money and it expire worthless or in other words its value is equal to zero.

9 The most common valuation is the estimation of the density functions of the so-called Log-Normal distribution. Other valuation methods involve various polynomial function estimations or estimations through Monte Carlo simulations if the partial differential equation does not yield analytical solutions.

10 For more on this issue, see ref. 2 above.

11 Jennergren, P.L. and Naslund, B. (1993) 'A Comment on Valuation of Executive Stock Options and the FASB Proposal', The Accounting Review, Vol. 68, No. 1, pp. 179-183.

12 Rubinstein, M. (1995) 'On the Accounting Valuation of Employee Stock Options', Journal of Derivatives, Vol. 3, No. 1, pp. 8-24.

13 For more on this issue, see notes 3 and 4, respectively.

14 We are explicitly assuming in order to use the Binomial model that the four-year time horizon can be expressed as a 24-step procedure (eg, 6 discrete steps per year $\times 4=24)$. Furthermore, the discount factor $\gamma$ is equal to 25 per cent and realistically reflects the nonexistence of marketability and transferability conditions in the ESOs market.

15 On 100,000 options the value differential between the Black and Scholes, the Binomial and the Pantos model is roughly $\$ 724,250$.

16 The analytical results that we have obtained clearly contradict the findings of the academic studies performed by Baril et al. (2005) "How to "Excel" at Options Valuation', Journal of Accountancy, Online Issues, December 2005, pp. 1-10; and Eaton Tim, V. and Prucyk, B.R. (2005) 'No Longer an "Option”', Journal of Accountancy, Online Issues, April 2005, pp. 1-8, respectively. 